\title{
Is venepuncture in neonatal research ethical?
}

\author{
V S Shah, M Al-Khannan, M W Quinn, J H Tripp
}

Department of Child

Health

Royal Devon and

Exeter Hospital

V S Shah

M Al-Khannan

M W Quinn

J H Tripp

Correspondence to:

Dr J H Tripp,

Department of Child Health,

Postgraduate Medical

School,

University of Exeter

Church Lane, Heavitree,

Exeter, EX2 5SQ.

Accepted 11 March 1997

Table 1 Parents'responses to questionnaire

\begin{tabular}{|c|c|c|c|c|}
\hline \multirow[b]{2}{*}{ Question } & \multicolumn{2}{|c|}{ Parent's report } & \multicolumn{2}{|c|}{ Doctor's report } \\
\hline & Number & $\begin{array}{l}\text { Per cent of } \\
\text { non-missing }\end{array}$ & Number & $\begin{array}{l}\text { Per cent of } \\
\text { non-missing }\end{array}$ \\
\hline \multicolumn{5}{|l|}{ Degree of parent's worry beforehand? } \\
\hline Not at all worried & 48 & 53 & 57 & 66 \\
\hline A little worried & 39 & 44 & 27 & 31 \\
\hline Yes - very worried & 3 & 3 & 3 & 3 \\
\hline Missing & 2 & & & \\
\hline \multicolumn{5}{|l|}{ Degree of parent's upset afterwards? } \\
\hline Not at all & 57 & 63 & 74 & 85 \\
\hline A little & 30 & 34 & 12 & 14 \\
\hline A lot & 3 & 3 & 1 & 1 \\
\hline Missing & 2 & & 5 & \\
\hline \multicolumn{5}{|l|}{ Perception of the test? } \\
\hline Worse than expected & 9 & 10 & & \\
\hline As I expected & 38 & 43 & & \\
\hline Better than expected & 41 & 47 & & \\
\hline Missing & 4 & & & \\
\hline \multicolumn{5}{|l|}{ Degree of upset of the baby? } \\
\hline Not at all & 54 & 60 & & \\
\hline A little & 29 & 32 & & \\
\hline A lot & 7 & 8 & & \\
\hline Missing & 2 & & & \\
\hline \multicolumn{5}{|l|}{ Difficulty of venepuncture? } \\
\hline First attempt & & & 71 & 81 \\
\hline Some difficulty, first vein & & & 8 & 9 \\
\hline Major difficulty or second vein & & & 1 & 1 \\
\hline Failed & & & 7 & 8 \\
\hline Missing & & & 5 & \\
\hline
\end{tabular}
$10 \%$ who thought it worse than expected. Seven babies were recorded as being very upset. Doctors tended to underestimate the degree of anxiety before the procedure and the level of distress afterwards.

Conclusions-Venepuncture in neonates seems to be acceptable to most parents and is associated with a favourable risk: benefit ratio using semiquantitative assessment of risk and benefit.

(Arch Dis Child 1997;77:F141-F142)

Keywords: venepuncture; risk:benefit ratio; nontherapeutic research
The 1992 British Paediatric Association guidelines define risk as: "the risk of causing physical disturbance, discomfort or pain or psychological disturbance to the child or his parents". ${ }^{1}$ It is accepted that children should never be exposed to significant risk of harm, either physical or psychological, during nontherapeutic research. ${ }^{2}$

Minimal risk is where the chance of serious injury or death is very remote and may be ignored, where the level of distress or clinical malaise is slight, or where there may be a chance of reaction which is itself trivial.

Venepuncture is the most common invasive procedure performed in children. This study assessed the acceptability and ethics of venepuncture in non-therapeutic research.

Results-Only three parents were very upset, and $47 \%$ reported the test as being better than they expected, compared with

\section{Methods}

Parents of normal, term, breastfed neonates were invited to participate in a project involving the use of a new vitamin $\mathrm{K}$ preparation. The need for blood sampling by venepuncture between days 6 and 10 of life (and in some cases again on day 28) was explained to parents, an information sheet given, and consent obtained. Mothers were present for the venepuncture(s); the Guthrie test was performed using part of the sample. Afterwards mothers and doctors were given a questionnaire to complete anonymously. Ninety two venepunctures were carried out in 69 neonates by one of two junior medical staff. Ninety parent questionnaires (two missing) and 87 doctor questionnaires (five missing) were identified. The project was approved by the local research ethics committee.

\section{Results}

A smaller number of parents were upset after seeing the procedure $(33,37 \%)$ than were worried beforehand $(42,46 \%)$, and only three were upset "a lot." There was some correlation between "degree of anxiety" before and "upset" after venepuncture, but a weaker correlation between the degree of upset of mother and baby; of the seven babies who were described as "upset a lot," only one mother described herself thus. Parents reported the test as being better than expected in $47 \%$ and worse than expected in $10 \%$ (table 1 ).

Doctors tended to underestimate the degree of anxiety before the procedure and the distress following it, judging by the responses to the parental questionnaire. Of the seven babies (three parents) who were more than a little upset, five had straightforward venepuncture at the first attempt without difficulty, while of the 18 babies for whom there was some difficulty, only two babies and three mothers were very upset. 
Twenty three of the 25 parents who were asked to participate for a second blood test on the 28th day of life agreed.

\section{Discussion}

The former British Paediatric Association guidelines for ethical conduct of medical research of children in 1992 caused alarm to many researchers by describing the risk of venepuncture in children as greater than minimal. This, together with the view that nontherapeutic research does not justify exposing children to more than minimal risk, might lead research ethics committees to ban nontherapeutic research involving venepunctures in children. A statement from the president, included in later editions as a foreword, addressed this issue.

A study of anxiety levels before and after blood sampling by venepuncture showed that appropriate preparation of parents and children with an explanatory and informative game was effective at reducing anxiety and stress during the procedure, ${ }^{4}$ and another that in most cases the experience produced trivial upset or no upset at all, and could sometimes have positive effects.

In this study we predicted that the level of anxiety of the mother would be critical rather than that of the infant. We confirmed a correlation between worry beforehand and degree of upset in mothers. Only three were "very worried" beforehand; of these, two were "very upset." Perhaps, surprisingly, there was less correlation between the degree of upset of the baby (as judged by the parent) and their own degree of upset, though all those whose babies was very upset, were at least a little upset themselves. There was an even poorer correlation between the degree of upset experienced by the parent, or baby's upset assessed by the parent, and the degree of difficulty experienced in performing the venepuncture.

The investigators underestimated parental anxieties, but may have coded as worried or upset only those they assessed as being unusually so. The doctors had not appreciated the distress of either of the parents who described themselves as "upset a lot" or the anxiety of those three who were very worried beforehand.

These data indicate that venepuncture should not be regarded as a procedure that carries more than minimal risk of a severe adverse reaction. Formal measurement of risk and benefit can, however, be assessed using the data collected by Rosser's scale of valuation of state of illness ${ }^{6}$ and adapted for quality adjusted life years. On the assumption that the upset caused by venepuncture (distress state 2 or 3 and disability state 0 ) lasted for 2 hours at most, we derived a very low value of 43/ $4380=0.01$. Against this risk we calculated benefit as the disutility avoided by a practice which would reduce the incidence and compli- cations of vitamin $\mathrm{K}$ deficiency bleeding. We postulated that the research would lead to the adoption of a safe alternative to intramuscular prophylaxis for vitamin $\mathrm{K}$ deficiency bleeding, more acceptable to parents and midwives, and resulting in greater use of prophylaxis. This would reduce the incidence of vitamin $\mathrm{K}$ deficiency bleeding and its complications. For a single case of severe cerebral palsy (distress 3, disability 6 , lifespan 40 years) associated with vitamin $\mathrm{K}$ deficiency bleeding, we calculated the total disutility as 8560 . The risk:benefit ratio is therefore 0.01:8560 which equals $1: 856000$ and is substantially less than the 1 per 100000 for a major adverse event that defines "more than minimal" risk. ${ }^{3}$ Thus even if all the infants who suffered any upset are counted as major adverse reactions and the unwanted outcome of cerebral palsy is avoided in only one child, the risk:benefit ratio is favourable. Multiplying the benefit utility score by the population risk over a number of years clearly makes the equation even more favourable.

The calculation addresses only the risk associated with the pain and distress of the procedure. It could be argued that in an older child the experience of venepuncture might result in a future fear of doctors or, in the situation of this study, a reluctance by mothers to agree to further venepuncture. The disutility value for this on Rosser's scale could be significant if an important diagnosis was missed as a result of this reluctance; this possibility is remote and hypothetical and therefore unmeasurable. Secondly, the calculation does not address the possibility of a rare (undescribed) complication arising from the venepuncture which would not be expected to occur in the very small number of tests involved in this study; again this is not calculable.

This exercise shows that while the scoring system is useful, it may not address major risks which cannot be calculated but are believed to exist. It does, however, offer an insight into the way in which the obvious "pain and distress" elements of procedures in children might be evaluated. We conclude that, on the basis of known risks and observed distress, venepuncture in the neonates in this study can be considered ethical on the basis of calculated risk:benefit ratios.

1 British Paediatric Association. Guidelines for the ethical conduct of medical research involving children. London: British Paediatric Association, 1992.

2 Royal College of Physicians. Guidelines on the practice of ethics committees in medical research involving human subjects. London, 1996.

3 Nicholson RH. Medical Research with Children: Ethics, Law, and Practice. Oxford: Oxford University Press, 1986.

4 Rodin J. Will this hurt? Research Monograph. London: Royal College of Nursing, Research Monograph, 1983.

5 Smith M. Taking blood from children causes no more than minimal harm. $\mathcal{F}$ Med Ethics 1985;11:127-31.

6 Rosser R, Kind PA. Scale of valuation of states of illness: is there a social consensus? Int $\mathcal{F}$ Epidemiol 1978;7:347-58. 